\title{
GMR
}

\section{IL-17 rs2275913 genetic variation contributes to the development of gastric cancer in a Chinese population}

\author{
B.L. Xu, Y.T. Li, S.X. Dong, J. Qi, H.M. Feng, L. Zi and D.Y. Yang \\ Department of General Surgery, Linyi People's Hospital, Linyi, China \\ Corresponding author: D.Y. Yang \\ E-mail: deyingyye@126.com \\ Genet. Mol. Res. 15 (2): gmr. 15027756 \\ Received September 30, 2015 \\ Accepted December 29, 2015 \\ Published June 3, 2016 \\ DOI http://dx.doi.org/10.4238/gmr.15027756
}

\begin{abstract}
The purpose of this hospital-based case-control study was to assess whether the interleukin (IL)-17 rs2275913 genetic variation can influence susceptibility to gastric cancer. Samples from a total of 202 gastric cancer patients and 237 controls were collected from the Linyi People's Hospital between March 2013 and March 2015. The IL-17 rs2275913 gene polymorphism was identified by polymerase chain reaction and restriction fragment length polymorphism. When compared with control subjects, gastric cancer patients were older in age $(\mathrm{OR}=3.89,95 \% \mathrm{CI}=2.55-5.95)$, male $(\mathrm{OR}=2.08,95 \% \mathrm{CI}=1.39$ $3.10)$, had a habit of alcohol consumption $(\mathrm{OR}=1.71,95 \% \mathrm{CI}=1.15$ 2.55), and were more likely to be infected with Helicobacter pylori (OR $=2.76,95 \% \mathrm{CI}=1.83-4.16$ ). We observed that the AA genotype of the IL-17 rs2275913 polymorphism resulted in a 2.32-fold risk of gastric cancer compared to the $\mathrm{GG}$ genotype $(\mathrm{OR}=2.32,95 \% \mathrm{CI}=1.20-4.54$; $\mathrm{P}=0.01)$. The AG combined with AA genotype of the IL-17 rs2275913 polymorphism had more risk of developing gastric cancer than the GG genotype $(\mathrm{OR}=1.50,95 \% \mathrm{CI}=1.01-2.23 ; \mathrm{P}=0.04)$. Moreover, the AA genotype of the IL-17 rs2275913 polymorphism was correlated with a higher risk of developing gastric cancer than the $\mathrm{GG}$ and $\mathrm{AG}$ genotypes combined $(\mathrm{OR}=2.01,95 \% \mathrm{CI}=1.08-3.79 ; \mathrm{P}=0.02)$. In conclusion,
\end{abstract}


the results of our study suggest that the IL-17 rs2275913 polymorphism could contribute to the risk of gastric cancer.

Key words: Interleukin-17; rs2275913; Polymorphism; Gastric cancer

\section{INTRODUCTION}

Gastric cancer is the fifth leading cause of cancer-related death globally among both men and women (International Agency for Research on Cancer, 2012). In 2012, 951,000 new cases of gastric cancer and 723,000 gastric cancer-related deaths were reported, and more than $70 \%$ were reported in developing countries (International Agency for Research on Cancer, 2012). Fifty percent of these new gastric cancer cases were reported in China (International Agency for Research on Cancer, 2012). The development of gastric cancer is associated with many environmental and lifestyle factors, including Helicobacter pylori infection, alcohol consumption, high salt diet, high consumption of pickled vegetables, and obesity (Houghton and Wang, 2005; van den Brandt and Goldbohm, 2006). Moreover, previous studies have reported that genetic factors also contribute to the development of gastric cancer, such as misregulation of miR-146a, miR-196a2, interleukin (IL)-10, prostate stem cell antigen, and many DNA repair genes (Geng et al., 2015; Ji et al., 2015; Kumar et al., 2015; Wei et al., 2015).

IL-17 is the founding member of a novel family of cytokines, and this gene is reported to be associated with susceptibility to many inflammatory-related diseases and cancers (Wu et al., 2013). The rs2275913 single nucleotide polymorphism (SNP) was identified in IL-17A and has been reported to be associated with various types of cancer, such as hepatocellular carcinoma, acute myeloid leukemia, colorectal cancer, cervical cancer, and bladder cancer (Quan et al., 2012; Zhou et al., 2013; Omrane et al., 2014; Wróbel et al., 2014; Xi et al., 2015). Many studies have linked the IL-17 rs2275913 SNP to gastric cancer, but their results are inconsistent (Wang et al., 2014; Gao et al., 2015; Hou and Yang, 2015; Long et al., 2015). In our study, we performed a hospital-based case-control study to assess whether the IL-17 rs2275913 genetic variation could influence susceptibility to gastric cancer in a Chinese population.

\section{MATERIAL AND METHODS}

\section{Patients}

Two hundred and two gastric cancer patients were randomly and consecutively selected from the Linyi People's Hospital during the period of March 2013 to March 2015. All gastric cancer patients received upper gastrointestinal endoscopy examination and their biopsy specimens were diagnosed by two clinical pathologists. Two hundred and thirty-seven subjects without tumors were consecutively collected from the Linyi People's Hospital during the period of March 2013 to March 2015 and served as healthy controls. The exclusion criteria for gastric cancer patients and control subjects were a history of other malignant tumors, recurrent tumors, or presence of any infectious disease.

The demographic, lifestyle, and clinical characteristics were collected from a self-designed questionnaire and medical records. The data included gender, age, alcohol consumption, tobacco use, first-generation family history of cancer, and incidence of $H$. pylori infection. Prior to participating into this study, each subject agreed to provide $5 \mathrm{~mL}$ peripheral blood and signed an informed consent form. Our study was approved by the Ethics Committee 
of the Linyi People's Hospital and our study was conducted according to the standards of the Declaration of Helsinki.

\section{DNA extraction and genotyping}

DNA extraction was performed using the TIANamp Blood DNA Kit (Tiangen, Beijing, China) according to the manufacturer protocols. The genotyping of the IL-17 rs2275913 SNP was performed by polymerase chain reaction (PCR) coupled with restriction fragment length polymorphism analysis. The forward and reverse primer sequences used to detect the IL-17 rs2275913 SNP were 5'-GCAGCTCTGCTCAGCTTCTAA-3' and 5'-TTCAGGGGTGACACCATTTT-3', respectively. The PCR fragments of IL-17 rs2275913 were subsequently digested with the BstENI restriction enzyme (Tiangen). The AA genotype produced one fragment of $155 \mathrm{bp}$, the GG genotype produced two fragments of 87 and $68 \mathrm{bp}$, and the AG genotype produced three fragments of 155, 87, and $68 \mathrm{bp}$. The PCR conditions were as follows: $95^{\circ} \mathrm{C}$ for $5 \mathrm{~min} ; 45$ cycles of $94^{\circ} \mathrm{C}$ for $30 \mathrm{~s}, 57^{\circ} \mathrm{C}$ for $30 \mathrm{~s}$, and $72^{\circ} \mathrm{C}$ for $30 \mathrm{~s}$; and a final extension at $72^{\circ} \mathrm{C}$ for $5 \mathrm{~min}$. The amplified products were examined by $2 \%$ agarose gel electrophoresis and observed under ultraviolet light.

\section{Statistical analysis}

All categorical variables (gender, age, alcohol consumption, tobacco use, family history of cancer, and $H$. pylori infection) are reported as number $(\mathrm{N})$ and percentage $(\%)$. The differences in general characteristics between gastric cancer patients and control subjects were analyzed using the chi-square $\left(\chi^{2}\right)$ test. Whether the IL-17 rs2275913 genotypes deviated from the Hardy-Weinberg equilibrium (HWE) was analyzed by the goodness-of-fit $\chi^{2}$ test. The association between general characteristics and gastric cancer risk was analyzed using univariate logistic regression analysis. The role of the IL-17 rs2275913 polymorphism in the risk of gastric cancer based on codominant, dominant, and recessive models was analyzed by multiple-logistic regression analysis. Odds ratio (OR) and 95\% confidence intervals (CIs) were used to describe the results. SPSS 16.0 (SPSS Inc., Chicago, IL, USA) was used to perform statistical analysis. $\mathrm{P}<0.05$ were taken as a statistically significant.

\section{RESULTS}

The general information of study subjects is shown in Table 1 . The mean age of gastric cancer patients and control subjects were $56.45 \pm 10.47$ and $49.52 \pm 12.79$ years, respectively. There were 77 females and 125 males in the gastric cancer patient group, and 133 females and 104 males in the control group. When compared with control subjects, gastric cancer patients were more likely to be older in age $(\mathrm{OR}=3.89,95 \% \mathrm{CI}=2.55-5.95)$, male $(\mathrm{OR}=2.08,95 \% \mathrm{CI}$ $=1.39-3.10)$, have a habit of alcohol consumption $(\mathrm{OR}=1.71,95 \% \mathrm{CI}=1.15-2.55)$, and be infected with $H$. pylori $(\mathrm{OR}=2.76,95 \% \mathrm{CI}=1.83-4.16)$.

In gastric cancer patients, there were 78 (38.61\%), 91 (45.05\%), and $33(16.34 \%)$ cases of the AA, AG and GG genotypes, respectively. In control subjects, there were 115 (48.52\%), $101(42.62 \%)$, and $21(8.86 \%)$ cases of the AA, AG, and GG genotypes, respectively (Table $2)$. By the chi-square test, there was a significant difference in genotype distributions of IL-17 rs2275913 between patients and controls $\left(\chi^{2}=7.54, \mathrm{P}=0.02\right)$. The IL-17 rs2275913 genotype frequencies in the gastric cancer patients and control subjects were in line with HWE, and 
the $\mathrm{P}$ values were 0.46 and 0.86 for gastric cancer patients and control subjects, respectively. Moreover, the minor allele frequency of the IL-17 rs2275913 SNP in controls was in good agreement with that in the dbSNP database (http://www.ncbi.nlm.nih.gov/projects/SNP/).

Table 1. General information on gastric cancer patients and control subjects.

\begin{tabular}{|c|c|c|c|c|c|c|c|}
\hline Variables & Patients & $\%$ & Controls & $\%$ & $\chi^{2}$ test & OR $(95 \% \mathrm{CI})$ & $\mathrm{P}$ value \\
\hline \multicolumn{8}{|c|}{ Age (years) } \\
\hline$<50$ & 86 & 42.57 & 176 & 74.26 & & 1.0 (Ref.) & - \\
\hline$\geq 50$ & 116 & 57.43 & 61 & 25.74 & 0.01 & $3.89(2.55-5.95)$ & $<0.001$ \\
\hline \multicolumn{8}{|l|}{ Gender } \\
\hline Female & 77 & 38.12 & 133 & 56.10 & & 1.0 (Ref.) & - \\
\hline Male & 125 & 61.88 & 104 & 43.90 & 14.16 & $2.08(1.39-3.10)$ & $<0.001$ \\
\hline \multicolumn{8}{|c|}{ First generation family cancer history } \\
\hline No & 185 & 91.58 & 226 & 95.54 & & 1.0 (Ref.) & - \\
\hline Yes & 17 & 8.42 & 11 & 4.46 & 2.6 & $1.89(0.81-4.57)$ & 0.11 \\
\hline \multicolumn{8}{|c|}{ Alcohol consumption } \\
\hline Never & 96 & 47.52 & 144 & 60.89 & & 1.0 (Ref.) & - \\
\hline Ever & 106 & 52.48 & 93 & 39.11 & 7.71 & $1.71(1.15-2.55)$ & 0.01 \\
\hline \multicolumn{8}{|c|}{ Tobacco use } \\
\hline Never & 114 & 56.44 & 148 & 62.38 & & 1.0 (Ref.) & - \\
\hline Ever & 88 & 43.56 & 89 & 37.62 & 1.64 & $1.28(0.86-1.92)$ & 0.21 \\
\hline \multicolumn{8}{|c|}{ Helicobacter pylori infection } \\
\hline Negative & 64 & 31.68 & 133 & 55.94 & & 1.0 (Ref.) & - \\
\hline Positive & 138 & 68.32 & 104 & 44.06 & 26.32 & $2.76(1.83-4.16)$ & $<0.001$ \\
\hline
\end{tabular}

$\mathrm{OR}=$ odds ratio $; \mathrm{CI}=$ confidence interval.

Table 2. Genotype distributions of the IL-17 rs2275913 gene polymorphism in gastric cancer patients and controls.

\begin{tabular}{|c|c|c|c|c|c|c|c|c|c|c|}
\hline \multirow[t]{2}{*}{ IL-17 } & \multirow[t]{2}{*}{ Patients $(\mathrm{N}=202)$} & \multirow[t]{2}{*}{$\%$} & \multirow[t]{2}{*}{ Controls $(\mathrm{N}=237)$} & \multirow[t]{2}{*}{$\%$} & \multicolumn{2}{|c|}{$\mathrm{P}$ for HWE } & \multirow[t]{2}{*}{$\chi^{2}$ test } & \multirow[t]{2}{*}{$\mathrm{P}$ value } & \multicolumn{2}{|c|}{ Minor allele frequency } \\
\hline & & & & & In cases & In controls & & & In database & In controls \\
\hline rs2275913 & & & & & & & & & & \\
\hline $\mathrm{GG}$ & 78 & 38.61 & 115 & 48.52 & & & & & & \\
\hline AG & 91 & 45.05 & 101 & 42.62 & & & & & & \\
\hline AA & 33 & 16.34 & 21 & 8.86 & 0.46 & 0.86 & 7.54 & 0.02 & 0.2927 & 0.3016 \\
\hline
\end{tabular}

HWE $=$ Hardy-Weinberg equilibrium.

The association between the IL-17 rs2275913 genetic variation and risk of gastric cancer was evaluated (Table 3). In a codominant model, we found that the AA genotype of IL17 rs2275913 was associated with increased risk of gastric cancer when compared with the GG genotype $(\mathrm{OR}=2.32,95 \% \mathrm{CI}=1.20-4.54 ; \mathrm{P}=0.01)$. In a dominant model, the $\mathrm{AG}$ and $\mathrm{AA}$ genotypes of IL-17 rs2275913 combined was correlated with an elevated increased risk of gastric cancer compared to the $\mathrm{GG}$ genotype $(\mathrm{OR}=1.50,95 \% \mathrm{CI}=1.01-2.23 ; \mathrm{P}=0.04)$. In a recessive model, the AA genotype of IL-17 rs2275913 resulted in a 2.01-fold increased risk of gastric cancer compared to the $\mathrm{GG}$ and $\mathrm{AG}$ genotypes combined $(\mathrm{OR}=2.01,95 \% \mathrm{CI}=1.08-3.79 ; \mathrm{P}=0.02)$.

Table 3. Association between the IL-17 rs2275913 gene polymorphism and risk of gastric cancer.

\begin{tabular}{l|c|c|c|c|c|c}
\hline IL-17 & Patients (N =202) & $\%$ & Controls (N =237) & $\%$ & OR (95\%CI) & P value \\
\hline rs2275913 & & & & & & \\
\hline Codominant & & & & & & \\
\hline GG & 78 & 38.61 & 115 & 48.52 & 1.0 (Ref.) & - \\
\hline AG & 91 & 45.05 & 101 & 42.62 & $1.33(0.87-2.03)$ & 0.17 \\
\hline AA & 33 & 16.34 & 21 & 8.86 & $2.32(1.20-4.54)$ & 0.01 \\
\hline Dominant & & & & & & \\
\hline GG & 78 & 38.61 & 115 & 48.52 & 1.0 (Ref.) & - \\
\hline AG+AA & 124 & 61.39 & 122 & 51.48 & $1.50(1.01-2.23)$ & 0.04 \\
\hline Recessive & 169 & 83.66 & 216 & 91.14 & 1.0 (Ref.) & - \\
\hline GG+AG & 33 & 16.34 & 21 & 8.86 & $2.01(1.08-3.79)$ & 0.02 \\
\hline AA & & & & &
\end{tabular}

Adjusted for gender, age, alcohol consumption and Helicobacter pylori infection. 


\section{DISCUSSION}

It is generally known that chronic inflammation can play a critical role in the pathogenesis of gastric cancer (Merchant, 2005; Lee et al., 2013). Previous studies reported that the IL-17 gene is expressed by Th17 cells and modifies chronic inflammation, and SNPs in IL-17 may alter gene expression, thus changing protein function and contributing to cancer risk (Park et al., 2005; Dong et al., 2008). Here, we performed a hospital-based case-control study to assess whether the IL-17 rs2275913 genetic variation could influence susceptibility to gastric cancer, and we found that IL-17 rs2275913 genetic variations appear to be associated with an elevated risk of gastric cancer in a Chinese population.

It has been reported that the IL-17 rs2275913 SNP could influence the development of several kinds of cancers, such as cervical cancer, colorectal cancer, oral squamous cell carcinoma, papillary thyroid cancer, hepatocellular carcinoma, and acute myeloid leukemia (Wróbel et al., 2014; Lee et al., 2015; Li et al., 2015a,b; Nemati et al., 2015; Sun et al., 2015; Xi et al., 2015). Wróbel et al. (2014) conducted a study with 62 acute myeloid leukemia patients and 125 healthy controls in a Polish population, and they found that the IL-17A rs2275913 polymorphism appeared to be correlated with susceptibility to acute myeloid leukemia. Lee et al. (2015) performed a study with 94 patients with papillary thyroid cancer patients and 260 controls in Korean population, and they demonstrated that the IL-17A rs2275913 SNP could influence the development of thyroid cancer. Li et al. (2015b) performed a study with 121 oral squamous cell carcinoma patients and 103 healthy controls, and they suggested that the A allele of the IL-17A rs2275913 SNP resulted in an increased risk of oral squamous cell carcinoma compared to the wild-type genotype. Sun et al. (2015) reported that the IL-17A rs2275913 genetic variation plays a critical role in the etiology of cervical cancer in 306 cervical cancer patients and 354 control subjects. However, Nemati et al. (2015) suggested that the IL-17A rs2275913 genetic variation may reduce the risk of colorectal cancer. Xi et al. (2015) assessed the association between IL-17 genetic variations and hepatocellular carcinoma with 155 patients with hepatitis B-related hepatocellular carcinoma and 171 healthy controls, and they reported that the IL-17A rs2275913 SNP did not independently contribute to this cancer.

For the correlation between the IL-17 rs2275913 genetic variation and gastric cancer risk, several studies were performed in different populations and reported different results (Shibata et al., 2009; Arisawa et al., 2012; Qinghai et al., 2014; Wang et al., 2014; Zhang et al., 2014; Hou and Yang, 2015). Shibata et al. (2009), Arisawa et al. (2012) and Zhang et al. (2014) conducted studies in Japanese and Chinese populations, and they revealed that the IL17 rs2275913 genetic variation was significantly associated with a higher risk of gastric cancer when compared to the wild-type genotype. Another three case-control studies in Chinese populations reported that the IL-17 rs2275913 A allele was associated with increased risk for the development of gastric cancer (Qinghai et al., 2014; Wang et al., 2014; Hou and Yang, 2015). However, one case-control study and one meta-analysis study reported inconsistent results with the previously mentioned studies (Kutikhin et al., 2014; Li et al., 2015c), and several other studies demonstrated that the IL-17 rs2275913 genetic variation did not affect susceptibility to gastric cancer (Kutikhin et al., 2014; Li et al., 2015c). In the present study, we found that the AA genotype and the A allele of the IL-17 rs2275913 SNP appeared to be associated with a higher risk of developing gastric cancer. The discrepancies of the results among these studies may be due to differences in study populations, selection of cases and controls, or sample size. 
In conclusion, the results of our study suggest that the IL-17 rs2275913 polymorphism could contribute to gastric cancer risk, which suggests that this polymorphism could influence the etiology of gastric cancer. Further studies with varying ethnicities and larger sample size are required to verify the role of the IL-17 rs2275913 genetic variation in gastric cancer risk.

\section{Conflicts of interest}

The authors declare no conflict of interest.

\section{ACKNOWLEDGMENTS}

We thank the great help from staffs in Linyi People's Hospital, who help us to collect blood samples from study subjects.

\section{REFERENCES}

Arisawa T, Tahara T, Shiroeda H, Matsue Y, et al. (2012). Genetic polymorphisms of IL17A and pri-microRNA-938, targeting IL17A 3'-UTR, influence susceptibility to gastric cancer. Hum. Immunol. 73: 747-752. http://dx.doi. org/10.1016/j.humimm.2012.04.011

Dong LM, Potter JD, White E, Ulrich CM, et al. (2008). Genetic susceptibility to cancer: the role of polymorphisms in candidate genes. JAMA 299: 2423-2436. http://dx.doi.org/10.1001/jama.299.20.2423

Gao YW, Xu M, Xu Y, Li D, et al. (2015). Effect of three common IL-17 single nucleotide polymorphisms on the risk of developing gastric cancer. Oncol. Lett. 9: 1398-1402.

Geng P, Li J, Wang N, Ou J, et al. (2015). PSCA rs2294008 polymorphism with increased risk of cancer. PLoS One 10: e0136269. http://dx.doi.org/10.1371/journal.pone.0136269

Hou C and Yang F (2015). Interleukin-17A gene polymorphism is associated with susceptibility to gastric cancer. Int. J. Clin. Exp. Pathol. 8: 7378-7384.

Houghton J and Wang TC (2005). Helicobacter pylori and gastric cancer: a new paradigm for inflammation-associated epithelial cancers. Gastroenterology 128: 1567-1578. http://dx.doi.org/10.1053/j.gastro.2005.03.037

International Agency for Research on Cancer (2012). Stomach Cancer. Estimated Incidence, Mortality and Prevalence Worldwide in 2012. Available at [http://globocan.iarc.fr/old/FactSheets/cancers/stomach-new.asp]. Last updated November 26, 2015.

Ji HX, Chang WS, Tsai CW, Wang JY, et al. (2015). Contribution of DNA repair Xeroderma Pigmentosum group D genotype to gastric cancer risk in Taiwan. Anticancer Res. 35: 4975-4981.

Kumar S, Kumari N, Mittal RD, Mohindra S, et al. (2015). Association between pro-(IL-8) and anti-inflammatory (IL-10) cytokine variants and their serum levels and H. pylori-related gastric carcinogenesis in northern India. Meta Gene 6: 9-16. http://dx.doi.org/10.1016/j.mgene.2015.07.008

Kutikhin AG, Yuzhalin AE, Volkov AN, Zhivotovskiy AS, et al. (2014). Correlation between genetic polymorphisms within IL-1B and TLR4 genes and cancer risk in a Russian population: a case-control study. Tumour Biol. 35: 48214830. http://dx.doi.org/10.1007/s13277-014-1633-6

Lee DY, Hong SW, Chang YG, Lee WY, et al. (2013). Clinical significance of preoperative inflammatory parameters in gastric cancer patients. J. Gastric Cancer 13: 111-116. http://dx.doi.org/10.5230/jgc.2013.13.2.111

Lee YC, Chung JH, Kim SK, Rhee SY, et al. (2015). Association between interleukin 17/interleukin 17 receptor gene polymorphisms and papillary thyroid cancer in Korean population. Cytokine 71: 283-288. http://dx.doi.org/10.1016/j. cyto.2014.11.011

Li L, Tian YL, Lv XM, Yu HF, et al. (2015a). Association analysis of IL-17A and IL-17F polymorphisms in Chinese women with cervical cancer. Genet. Mol. Res. 14: 12178-12183. http://dx.doi.org/10.4238/2015.October.9.6

Li N, Zhang C, Chen Z, Bai L, et al. (2015b). Interleukin 17A and interleukin 17F polymorphisms are associated with oral squamous cell carcinoma susceptibility in a Chinese population. J. Oral Maxillofac. Surg. 73: 267-273. http://dx.doi. org/10.1016/j.joms.2014.09.009

Li Z, Liu Y, Cao D, Jiang M, et al. (2015c). IL-17A and IL-17F polymorphisms and gastric cancer risk: a meta-analysis. Genet. Mol. Res. 14: 7008-7017. http://dx.doi.org/10.4238/2015.June.26.10 
Long ZW, Yu HM, Wang YN, Liu D, et al. (2015). Association of IL-17 polymorphisms with gastric cancer risk in Asian populations. World J. Gastroenterol. 21: 5707-5718. http://dx.doi.org/10.3748/wjg.v21.i18.5707

Merchant JL (2005). Inflammation, atrophy, gastric cancer: connecting the molecular dots. Gastroenterology 129: 10791082. http://dx.doi.org/10.1053/j.gastro.2005.07.038

Nemati K, Golmoghaddam H, Hosseini SV, Ghaderi A, et al. (2015). Interleukin-17FT7488 allele is associated with a decreased risk of colorectal cancer and tumor progression. Gene 561: 88-94. http://dx.doi.org/10.1016/j. gene.2015.02.014

Omrane I, Marrakchi R, Baroudi O, Mezlini A, et al. (2014). Significant association between interleukin-17A polymorphism and colorectal cancer. Tumour Biol. 35: 6627-6632. http://dx.doi.org/10.1007/s13277-014-1890-4

Park H, Li Z, Yang XO, Chang SH, et al. (2005). A distinct lineage of CD4 T cells regulates tissue inflammation by producing interleukin 17. Nat. Immunol. 6: 1133-1141. http://dx.doi.org/10.1038/ni1261

Qinghai Z, Yanying W, Yunfang C, Xukui Z, et al. (2014). Effect of interleukin-17A and interleukin-17F gene polymorphisms on the risk of gastric cancer in a Chinese population. Gene 537: 328-332. http://dx.doi.org/10.1016/j. gene.2013.11.007

Quan Y, Zhou B, Wang Y, Duan R, et al. (2012). Association between IL17 polymorphisms and risk of cervical cancer in Chinese women. Clin. Dev. Immunol. 2012: 258293. http://dx.doi.org/10.1155/2012/258293

Shibata T, Tahara T, Hirata I and Arisawa T (2009). Genetic polymorphism of interleukin-17A and -17F genes in gastric carcinogenesis. Hum. Immunol. 70: 547-551. http://dx.doi.org/10.1016/j.humimm.2009.04.030

Sun LX, Wang XB and Huang XJ (2015). Association analysis of rs2275913G $>$ A and rs763780T $>C$ interleukin 17 polymorphisms in Chinese women with cervical cancer. Genet. Mol. Res. 14: 13612-13617.

van den Brandt PA and Goldbohm RA (2006). Nutrition in the prevention of gastrointestinal cancer. Best Pract. Res. Clin. Gastroenterol. 20: 589-603. http://dx.doi.org/10.1016/j.bpg.2006.04.001

Wang N, Yang J, Lu J, Qiao Q, et al. (2014). IL-17 gene polymorphism is associated with susceptibility to gastric cancer. Tumour Biol. 35: 10025-10030. http://dx.doi.org/10.1007/s13277-014-2255-8

Wei Y, Li L and Gao J (2015). The association between two common polymorphisms (miR-146a rs2910164 and miR196a2 rs11614913) and susceptibility to gastric cancer: A meta-analysis. Cancer Biomark. 15: 235-248. http://dx.doi. org $/ 10.3233 / \mathrm{CBM}-150470$

Wróbel T, Gębura K, Wysoczańska B, Jaźwiec B, et al. (2014). IL-17F gene polymorphism is associated with susceptibility to acute myeloid leukemia. J. Cancer Res. Clin. Oncol. 140: 1551-1555. http://dx.doi.org/10.1007/s00432-014-1674-7

Wu D, Wu P, Huang Q, Liu Y, et al. (2013). Interleukin-17: a promoter in colorectal cancer progression. Clin. Dev. Immunol. 2013: 436307. http://dx.doi.org/10.1155/2013/436307

Xi XE, Liu Y, Lu Y, Huang L, et al. (2015). Interleukin-17A and interleukin-17F gene polymorphisms and hepatitis B virus-related hepatocellular carcinoma risk in a Chinese population. Med. Oncol. 32: 355. http://dx.doi.org/10.1007/ $\underline{\text { s12032-014-0355-3 }}$

Zhang X, Zheng L, Sun Y and Zhang X (2014). Analysis of the association of interleukin-17 gene polymorphisms with gastric cancer risk and interaction with Helicobacter pylori infection in a Chinese population. Tumour Biol. 35: 15751580. http://dx.doi.org/10.1007/s13277-013-1217-x

Zhou B, Zhang P, Wang Y, Shi S, et al. (2013). Interleukin-17 gene polymorphisms are associated with bladder cancer in a Chinese Han population. Mol. Carcinog. 52: 871-878. http://dx.doi.org/10.1002/mc.21928 